Revista de

Contabilidade e

Organizações

www.rco.usp.br
DOI: http://dx.doi.org/10.11606/issn.1982-6486.rco.2018.141359

Journal of

Accounting and

Organizations

\title{
A Gestão Ordinária e suas práticas: o caso da Cafeteria Will Coffee
}

\section{The Ordinary Management and its practices: the case of the Will Coffee Shop}

Alexandre de Pádua Carrieria ${ }^{\text {; }}$ Denis Alves Perdigão ${ }^{\mathrm{b}}$; Paula Gontijo Martins ${ }^{\mathrm{a}}$; Ana Rosa Camillo Aguiar ${ }^{\mathrm{a}}$

${ }^{a}$ Universidade Federal de Minas Gerais

${ }^{b}$ Universidade Federal de Juiz de Fora

Palavras-chave

Gestão ordinária.

Cotidiano.

Práticas.

Cafeteria Will Coffee.
Keywords

Ordinary management.

Everyday life.

Will Coffee Shop.
Informações do Artigo

Recebido: 05 de dezembro de 2017

Aceito: 19 de novembro de 2018

Publicado: 26 de novembro de 2018

\begin{abstract}
Resumo
O presente artigo tem por objetivo contribuir para o entendimento do conceito de gestão ordinária (Carrieri, Perdigão \& Aguiar, 2014), por meio do estudo de uma pequena organização familiar, a Cafeteria Will Coffee. A gestão ordinária não é apresentada como um 'modelo' alternativo de gestão, tampouco como um método formal de pesquisa, mas como uma crítica aos modelos e postulados gerenciais dominantes, que buscam simplificar a realidade complexa do ambiente sócio-organizacional. Ao tomar como caso de estudo uma cafeteria aberta em um bairro operário de Contagem (MG), cujas peculiaridades tornaram sua história pública, noticiada em diversos veículos da mídia jornalística e especializada, busca-se evidenciar e ressaltar aspectos rotineiramente silenciados, desprezados, ou apagados das complexas narrativas que não cabem nos modelos habituais, como a espontaneidade, o não planejamento e a improvisação. Conclui-se que a gestão ordinária colabora com a área de Estudos Organizacionais ao possibilitar a recuperação de outras experiências de gestão, visibilizando aos 'sujeitos' comuns e se interessando por suas histórias, discursos, e práticas, recuperando o direito de eles serem vistos como gestores e produtores de conhecimento.
\end{abstract}

\begin{abstract}
This paper aims to contribute to the understanding of the concept of ordinary management (Carrieri, Perdigão \& Aguiar, 2014), through the study of a small family organization, the Will Coffee Shop. Ordinary management is not presented as an alternative 'model' of management, as little as a formal research method, but as a critique of the dominant managerial models and postulates that seek to simplify the complex reality of the socio-organizational environment. When taking as a case study a cafeteria opened in a working-class neighborhood of Contagem (MG), whose peculiarities have made its history public, reported in several specialized media vehicles, it seeks to highlight and emphasize aspects routinely silenced, despised, or erased of the complex narratives that do not fit into the usual models, such as spontaneity, non-planning and improvisation. It is concluded that ordinary management collaborates with the area of Organizational Studies by enabling the recovery of other management experiences, giving voice to the common 'subjects' and becoming interested in their histories, discourses, and practices, recovering the right of them as managers and producers of knowledge.
\end{abstract}

\section{Implicações práticas}

A atuação de contadores, analistas, peritos e consultores é estigmatizada em papéis definidos como adequados pelos modelos do mainstream do management. $\mathrm{O}$ estudo parte da visão crítica visando desconstruir esses pressupostos, aprofundando a aplicação do conceito de 'gestão ordinária' para trazer à tona o cotidiano da organização e de seus profissionais. Com isso, desestigmatiza papéis de super decisores e sugere que sejam observados os indivíduos comuns, que fazem o dia a dia da organização.

Copyright $(\subset) 2018$ FEA-RP/USP. Todos os direitos reservados

\section{INTRODUÇÃO}

A gestão ordinária refere-se à gestão realizada "no cotidiano dos negócios ordinários, dos pequenos negócios, e é uma prática social e cultural formada por uma pluralidade de códigos, referências, interesses pessoais e relacionais" (Carrieri, Perdigão \& Aguiar, 2014, p. 700).

Autor Correspondente: Tel. (31) 988545955

E-mail: aguiar.paduacarrieri@terra.com.br (A. R. C. Aguiar); lafeta.perdigao@gmail.com (D. Perdigão); pgontijomartins@gmail.com (P. G. Martins); aguiar. paduacarrieri@terra.com.br (A. de P. Carrieri)

Universidade Federal de Minas Gerais. Av. Pres. Antônio Carlos, 6627 - Pampulha, Belo Horizonte - MG, 31270-901, Brasil. 
Tal gestão é realizada pelas pessoas comuns, 'gente sem história', como define Martins (2008), com suas diversas formas de fazer e saber, que por vezes são dissonantes de modelos preestabelecidos, pretensamente 'universais' para qualquer sujeito e realidade (Carrieri, Perdigão \& Aguiar, 2014). Como exemplo, podemos citar os autores tais como Philip Kotler em marketing, Michael Porter em estratégia organizacional, ou Peter Drucker em gestão empresarial, que desenham modelos que são ditos universais e que muitas vezes não são condizentes com a realidade do gestor que administra negócios comuns (Micklethwait \& Wooldridge, 1998).

Neste sentido, a gestão ordinária é uma possibilidade de crítica aos modelos gerenciais institucionalizados pelo mainstream da Administração e das Ciências Contábeis, ao que Wood Jr. e Paula (2002a; 2002b) chamaram de pop-management. Os discursos desses modelos defendem um conhecimento tido como puro, neutro, absoluto e universal (Mattos, 2009; Bertero et al., 2013). A crítica ao mainstream perpetuado por editores e autores, gurus e analistas, denominada de "literatura maior" (Deleuze \& Guattari, 1978) em administração, perpetuam formas de pensar, que escondem e apagam um cotidiano complexo, salpicado de combinações de ações não racionais (Foucault, 1987; Didi-Huberman, 2011) ou formas subversivas de se pensar.

Ainda, a gestão ordinária critica a visão funcionalista das organizações, em que os procedimentos devem estar padronizados e adequados segundo normas, por vezes distantes da realidade concreta dos executores. Tal visão não considera que a padronização pode ser incompatível com a diversidade de organizações existentes, as quais diferem entre si quanto à forma, estrutura, pessoas, contexto e história (Carrieri, Perdigão \& Aguiar, 2014; Carneiro \& Barros, 2017; Barros et al., 2011).

A busca pela padronização segue a lógica de adoção e implementação de conhecimentos similares (Corbertt-Etchevers \& Mounoud, 2011). Porém, o discurso do 'management' não é consumido da forma como seus produtores idealizam (Micklethwait \& Wooldridge, 1998; Corbertt-Etchevers \& Mounoud, 2011). Assim como os leitores de um livro podem interpretar de múltiplas formas a obra do escritor, diante do repertório cultural e social que carregam, os indivíduos nas organizações internalizam e decodificam as mensagens transmitidas de formas diferentes, interagindo diferentemente com discursos, técnicas e práticas adotadas pela cúpula organizacional, tornando o cotidiano de trabalho rico em possibilidades. Com este argumento, não pretendemos desconsiderar a influência que as estruturas exercem na construção social da realidade (Berger \& Luckmann, 2011), mas enfatizar que, mesmo sobre tal influência, há uma gama de maneiras de pensar, interpretar e fazer, de se submeter ou resistir, tornando o cotidiano organizacional dinâmico, e abrindo uma diversidade de opções em seu campo de práticas.

Portanto, não coadunamos com a perspectiva determinista do estruturalismo, embora reconheçamos que estas estruturas, criadas pelo próprio conjunto social, exercem influência na sociedade tanto quanto são influenciadas e modificadas por ela ao longo do tempo. Os indivíduos nas organizações usam, transformam e dão outros significados às (velhas) ideias e criam suas próprias práticas gerenciais.

A realidade é construída e resulta de processos histórico-sociais. A realidade para um indivíduo é fruto de regimes discırsivos que constroem proposições por meio de um conjunto de regras (Foucault, 1987). Tais regimes discursivos mudam com a época, existindo uma variedade deles, com regras específicas, histórica e culturalmente construídas" (Pinheiro, Carrieri \& Joaquim, 2013). Portanto, o estudo da Administração exige a atribuição de caráter histórico de conceitos e categorias, aceitando a transitoriedade do conhecimento (Carneiro \& Barros, 2017; Wanderley, Fiarros, Costa \& Carrieri, 2017; Barros \& Carrieri, 2015), pois as 'verdades' são localizadas no espaço e no tempo, nãc existindo uma universalidade das 'asserções de verdade'.

A gestão das organizações seria então um fenômeno plural, que inclui como participantes dessas organizações us indivíduos 'menos lembrados' (Carvalho, 2006), o que chamamos aqui de sujeitos comuns. Estes indivíduos geram e usam o chamado conhecimento popular, com suas práticas próprias de organização de atividades em seus empreendimentos comerciais de pequeno porte. Porém, comparados aos procedimentos ditos como 'adequados' na visão funcionalista, são estigmatizados e rotulados como amadores, improvisados, sem profissionalismo, sem credibilidade (Carvalho, 2006; Xavier, Barros, Cruz \& Carrieri, 2012; Barros \& Carrieri, 2015). Apesar da pressão funcionalista, alguns desses indivíduos gerem seus negócios preservando práticas e tradições (Carvalho, 2006), enquanto outros criam alternativas à própria maneira para inovar as práticas cotidianas. Ambas as possibilidades podem não ter vínculos com o modelo dominante funcionalista de gestão (Carvalho, 2006; Carrieri, Perdigão \& Aguiar, 2014). 
A racionalidade instrumental de áreas como Administração, Contabilidade, Economia e Direito domina outras formas construídas na sociedade (Ramos, 1981; Benjamin, 2006). Partimos do conceito de gestão ordinária, exercida pelos sujeitos comuns e suas estratégias e táticas cotidianas de sobrevivência (De Certeau, 1994; De Certeau, Giardi \& Mayol, 1996), para apresentar nova perspectiva de análise sobre as práticas de gestão. Para tal, apresentamos neste artigo o caso real de uma pequena organização familiar e o estudamos sob a perspectiva da gestão ordinária, evidenciando seus pontos de não identificação com os postulados funcionalistas.

\section{INTRODUÇÃO À GESTÃO ORDINÁRIA DO COTIDIANO}

$\mathrm{O}$ aspecto cotidiano da vida tem sido utilizado como pano de fundo teórico, metodológico e até mesmo epistemológico em diversas áreas de estudos. De certa maneira, seu uso na História a partir do século XX elucidou diversas possibilidades de reflexão e apropriação em diversas áreas. Dentro da História, por exemplo, se observa a substituição de uma história única, contemplativa e universal, que de certa maneira refletia histórias particulares de certos ramos privilegiados, por uma história que visa valorizar a riqueza subjetiva das diversas circunstâncias da vida (Del Priore, 1997; Guarinello, 2004.).

O estudo do cotidiano como 'literatura menor' vem em contraposição ao chamado mainstream, ou 'literatura maior', e, portanto, assume uma postura crítica segundo a abordagem pós-estruturalista que orienta os autores deste trabalho. Nesta abordagem, o foco está na rotina das pessoas que não ocupam cargos importantes ou poder diferenciado, ou que não pertencem a classes e extratos privilegiados da sociedade. Trata da vida corriqueira do homem comum, e não de questões grandiosas, como das estratégias de líderes e executivos. Destaca-se que não se pretende aqui universalizar a gestão do cotidiano, apenas investigar como essa gestão funciona, o que ela pode fazer, o que ela produz de conhecimento e práticas que possibilitam a sobrevivência dos negócios, das famílias.

Entender o cotidiano gerencial permite que se revelem os atos, os gestos e as palavras do sujeito comum, ou do ordinário (Martins, 2008). Ao invés de grandes narrativas e histórias traçadas como universais, ou, ao invés de tipificações de modelos de 'Homem', observa-se o sujeito comum. Dessa forma, apreende-se como esse sujeito comum gere os seus próprios empreendimentos e projetos, que facilmente se conectam com outras importantes dimensões sociais de sua vida, como a própria família. Ao invés de assumir uma racionalidade única, da homogeneização empobrecedora e limitada, o mundo cotidiano é observado como ilimitadas racionalidades de diversas temporalidades concomitantemente presentes (Levigard \& Barbosa, 2010).

A gestão ordinária possibilitaria uma melhor compreensão sobre a organização do pequeno negócio familiar e de como esse negócio e a família se misturam (Carrieri, Perdigão \& Aguiar, 2014). Não estamos falando somente no estudo dos hábitos e rotinas próprias do cotidiano, mas, também, do movimento das práticas criadas pelas pessoas, marcadas pela pluralidade e suas ambiguidades, pela multiplicidade de interpretações e experiências, bem como de resistências aos processos aos quais estão submetidas (Matos, 2002).

O cotidiano não deve ser estudado como "uma repetição mecânica e imutável de gestos, tradições ou costumes, na realidade ele é reinventado sempre a cada refazer de atitude que o homem e a mulher desempenham na vida em sociedade" (Duran, 2007, p. 118). Mas deve ser visto como portador de "[...] vozes a diversos sujeitos históricos elaborando a construção e desconstrução da história, partindo de novas fontes e de novos objetos" (Duran, 2007, p. 118).

O cotidiano é um espaço de luta. O consumo de ideias, valores e produtos pelas pessoas não ocorre por práticas passivas e uniformes, em conformidade com as instituições dominantes. Aqui, o cotidiano é entendido como um 'território' socialmente construído, em que indivíduo e grupo se relacionam na construção das identidades, de modo a transformar o 'espaço' em 'lugar simbólico' (De Certeau, 1994; De Certeau, Giardi \& Mayol, 1996). Ao terem contato com 'fissuras' das estruturas existentes, espaços heterotópicos segundo Foucault (2013, p. 28), os indivíduos no cotidiano usam (micro) exercícios, táticas de oposição e afrontamentos, para enfrentarem os conceitos impostos e dominantes.

Entre eles, destacamos a oposição aos discursos oficiais e o uso de táticas e práticas fortalecedoras ou subversivas, também presentes na verbalização, na reação e na emoção das narrativas dos sujeitos ordinários (Duran, 2007). Tais brechas abrem possibilidades para práticas de liberdade (Hjorth, 2005; Foucault, 2013) no momento em que possibilitam o deslocamento do que é dado como padrão, como o modelo tradicional de gestão, permitindo a experimentação de relações distintas. Assim, a experimentação de oportunidades antes não imaginadas recria o que estava estabelecido como norma e reescreve o conceito de gestão (Hjorth, 2005). 
As resistências, enquanto prática (ação e discursiva) no cotidiano, movimentam as formas de organizar e gerir os negócios, as família e até nós mesmos. De forma não deliberada, tais práticas alterariam até mesmo o funcionamento do sistema, que opera segundo a racionalidade funcionalista, mas que é deturpado e recebe novos significados (Sousa Filho, 2002).

O desafio do pesquisador ao desbravar o cotidiano reside na exploração de histórias de 'gente sem história' (Matos, 2002). 'Gente sem história', sujeitos comuns, são em geral excluídos da narrativa gerencial por não terem uma história homérica. Aprender a gestão ordinária empreendida pelo sujeito comum é interpretar, nos inúmeros discursos dispersos, as estratégias e táticas de sobrevivência e resistências no cotidiano dos tidos como pequenos (Carrieri, Perdigão \& Aguiar, 2014), no entanto, nada menos importantes.

Interessante exemplo da possibilidade de mudança de conceitos de organização é dado em Hjorth (2005). $\mathrm{O}$ autor analisou a intervenção de um grupo de artistas no cotidiano de uma empresa, em que os funcionários criaram um espaço suspenso no pátio do local de trabalho para descansar, jogar, trocar informações e operar uma rádio local. Tal iniciativa solucionou o problema de comunicação identificado pela equipe. Essa perspectiva contrapõe a dominante racionalidade econômica no ambiente de trabalho, abrindo espaço para outras práticas cotidianas até então silenciadas e apagadas do discurso (Hjorth, 2005).

Sob a aparente banalidade de práticas cotidianas se esconde uma extraordinária criatividade (Hjorth, 2005; Corbett-Etchevers \& Mounoud, 2011). Porém, os espaços-tempos únicos para criatividade não surgem do nada, como algumas teorias sobre o empreendedorismo defendem; nem podem ser copiados ou modelados. Deve-se permitir a liberdade criativa (em espaço e tempo determinados) para reinvenção das práticas diárias (Hjorth, 2005). Os comportamentos rotineiros apresentam tanto submissão ao funcionalismo como também certa experimentação com resistência e criatividade.

Essa criatividade pode ser observada também no cotidiano das práticas da contabilidade (Jeacle, 2009; Ahrens, 2009). Para estes autores, o estudo do dia a dia contábil envolve as tecnologias de cálculo e as resistências aos padrões e benchmarking das empresas. O cotidiano contábil transforma as atividades organizacionais em rotinas, mas o criar é essencial para a atualização das práticas (Ahrens, 2009).

Por fim, para nós, o cotidiano só pode ser pensado como um espaço onde desenvolvem-se inúmeras relações sociais de poder (De Certeau, 1994; De Certeau, Giardi \& Mayol, 1996). O cotidiano enquanto categoria de estudo não pode ser compreendido como algo a priori naturalizado, mas deve ser interpretado como uma produção da ação humana expressando as relações sociais existentes. As pessoas, os sujeitos da pesquisa, constroem suas práticas organizativas a partir de experiências no cotidiano do trabalho, do exercício de suas atividades cotidianas, aprendendo com erros e acertos (Holanda, 2011). As trajetórias cotidianas narradas são produtos de intervenções humanas, materializações de projetos elaborados por sujeitos históricos e sociais.

\section{O CASO DA CEFETERIA WILL COFFEE}

Como a gestão ordinária não se adequa a um modelo de gestão, com parâmetros, procedimentos e diretrizes predeterminadas a serem seguidas para o atingimento de objetivos organizacionais, mas, sim, uma forma de 'olhar', de perceber, de analisar e de reconhecer outras formas de gerir pequenos negócios familiares, com o uso da intuição, da criatividade, do instinto de sobrevivência, das emoções e dos sentimentos mais próximos de uma racionalidade substantiva, apresentamos ao leitor um caso que nos permite demonstrar a prática da gestão ordinária. Trata-se da Cafeteria Will Coffee, aberta em 2012 em um bairro operário da cidade de Contagem/MG. As características peculiares que envolvem o surgimento, o funcionamento e o sucesso econômico deste pequeno negócio familiar tornaram sua história pública, noticiada em diversos veículos da mídia jornalística e especializada.

Com base no testemunho de Marcos e Michele (proprietários do empreendimento), concedido por meio de entrevista aos autores, apresentamos os pontos relevantes do caso sob a ótica da gestão ordinária. E para facilitar a contraposição à perspectiva gerencialista, elegemos organizar estes pontos segundo a estrutura da ferramenta CANVAS. Modelo utilizado para a avaliação de viabilidade de novos negócios e que será melhor descrito e detalhado no subitem posterior.

No que tange à metodologia, adotamos a narrativa como fonte para análise dos dados aqui apresentados. Assim, pretende-se analisar a função mobilizadora das narrativas organizacionais, salientando sua força enquanto portadora de uma autoridade intrínseca, que nos convida a investigar sua capacidade argumentativa e sua função de comunicação (Santos, 2014). Tal abordagem foi introduzida aos estudos comunicacionais na década de 1990, resultante de um processo de reinterpretação das organizações, que fez emergir uma série de teorias alternativas. Uma delas, a chamada teoria narrativa pós-moderna, em que a história ocupa o papel principal (Santos, 2014). 
Coerente com as reflexões teóricas deste trabalho, as narrativas contribuem para o surgimento de abordagens teórico-metodológicas mais criativas, intuitivas e diferentes para as pesquisas, já que não há preocupações com universo e amostragem do ponto de vista estatístico. Não pretendemos, dessa forma, fazer nenhum tipo de generalização do caso analisado. Ao contrário, buscamos evidenciar "particularidades percebidas à luz de eventos específicos que se desenrolaram ao longo do processo" (Saraiva, 2007, p.122).

Fischer et al. (2007) destacam a biografia, os estudos de caso e os estudos etnográficos como narrativas não-ficcionais, que são, para os autores, um campo de pesquisa já bastante desenvolvido em organizações. As narrativas tomam formas de histórias, textos, discursos e atos narrativos, como falas e escritas, que possibilitam o trabalho com abordagens objetivistas, subjetivistas e com triangulações e metatriangulações entre ambos.

A narrativa possibilita teorizar a partir das trajetórias de um indivíduo e suas respectivas construções de memórias, pois constitui fonte de realidade (Saraiva, 2007). Como exemplo, Fischer et al. (2007) citam o estudo sobre uma organização como o Mosteiro de São Bento da Bahia, realizada por Carvalho e Fischer (2006). Pôde-se estudar a trajetória do mosteiro, fundadora da organização modernista, a partir de depoimentos dos abades e monges, colhidos diretamente, ou por meio de escritos dispersos no tempo, permitindo a desconstrução e reconstrução dos discursos de sujeitos imersos no claustro. Segundo esta perspectiva, ouvimos as histórias de Marcos e Michele sobre o início e a construção da cafeteria, bem como sobre o dia a dia, os fatores de sucesso e desafios que enfrentam.

\section{WILL COFFEE: entre o ordinário e o mainstream}

Para aprofundamento e melhor visualização do que estamos discutindo como gestão ordinária, elegemos um caso que julgamos emblemático e o analisamos segundo as categorias de uma ferramenta gerencialista, pertencente ao mainstream, o qual criticamos. Julgamos que, dessa forma, podemos sinalizar com maior precisão os pontos de inflexão, para os quais chamamos atenção. Intercalamos as categorias do CANVAS, nossas análises e as falas coletadas em entrevistas com Marcos e Michele. Buscamos, assim, construir um diálogo com as três dimensões da pesquisa. No entanto, estas categorias apenas servem como norte de comparação, pois seria impossível adequar o caso ao modelo. Sendo esta a principal reflexão que desejamos levantar.

Elegemos utilizar o método CANVAS, apresentado na Figura 1, como suporte de nossas elaborações, pois ele é hoje uma das ferramentas utilizadas pelo Serviço Brasileiro de Apoio às Micro e Pequenas Empresas (SEBRAE) para avaliar a viabilidade de um empreendimento. Dessa forma, adotamos as 9 (nove) categorias e perguntas desse método para guiar nossas reflexões sobre o caso específico.

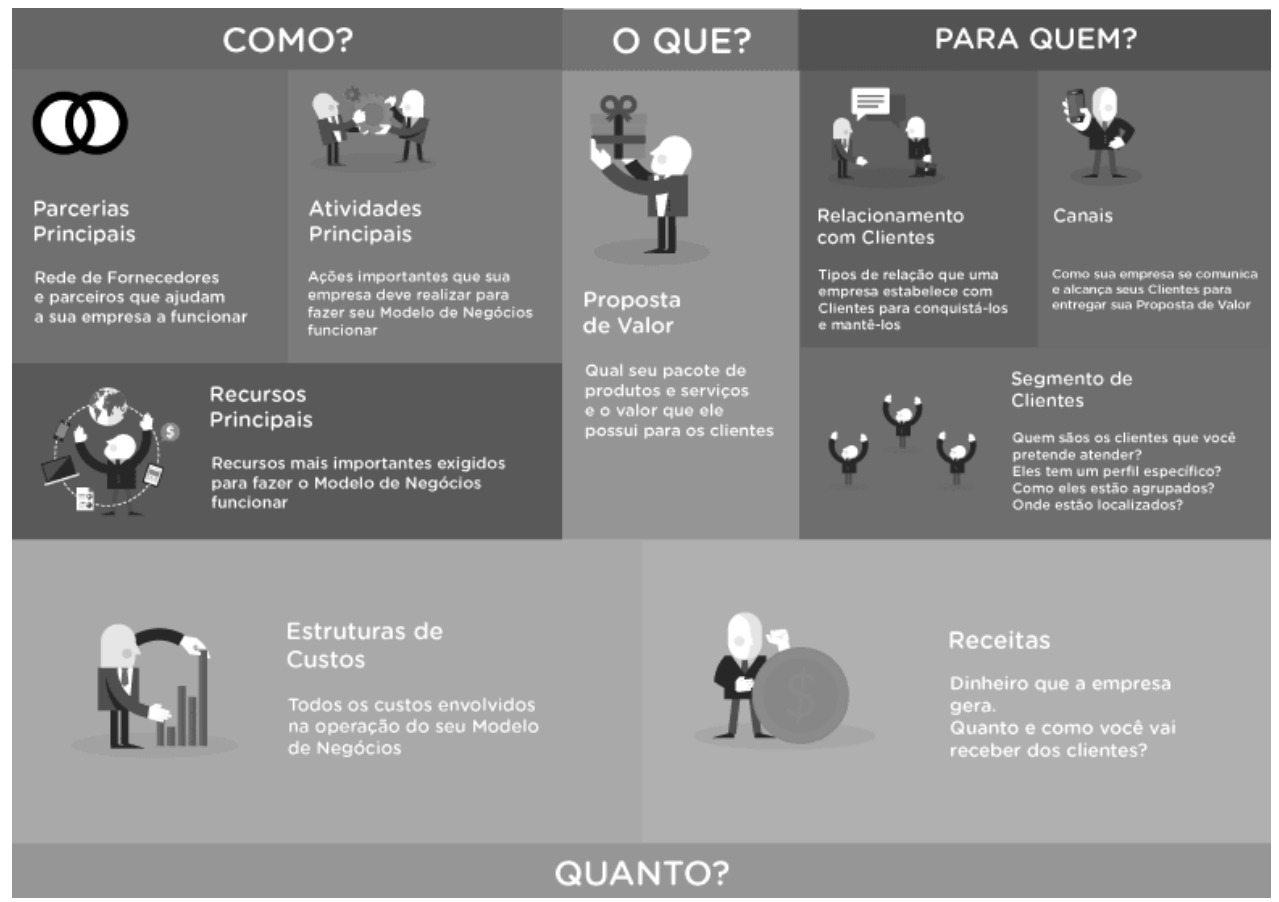

Figura 1. Modelo de Negócios CANVAS

Fonte: Franklin, 2016. 
O CANVAS estrutura-se no preenchimento de um quadro com 9 (nove) perguntas. O empreendedor deve seguir, passo a passo, respondendo as perguntas, observando a coerência que cada uma tem em relação a anterior. Ao final, é preciso que o quadro seja visto como um todo, em que todas as respostas sejam coerentes e tenham sentido quando analisadas em conjunto. O CANVAS é uma ferramenta de planejamento, controle e prospecção de investimentos, para saber se a ideia inicial é lucrativa, se proporciona retorno aos acionistas e se tem coerência com o mercado que almeja. Planejamento, avaliação e controle, os três pilares para a estruturação organizacional à qual fazemos ressalvas.

A seguir apresentamos cada uma das categorias de planejamento de negócios do CANVAS e as confrontamos com os dados levantados no caso da Cafeteria Will Coffee, demonstrando como se afastam da proposta do mainstream e são melhor compreendidos sob a perspectiva da gestão ordinária.

\subsection{Proposta de valor: o que sua empresa vai oferecer para o mercado que realmente terá valor para os clientes?}

O mainstream gerencialista advoga que os empreendedores devem elaborar um estudo prévio quanto aos seus futuros empreendimentos de forma a avaliar a viabilidade, mitigando riscos e evitando perdas financeiras. No método CANVAS, a primeira análise permite aos empreendedores refletir, de forma racional, sobre a adequação do futuro negócio ao seu mercado. No caso da Cafeteria Will Coffee isto não ocorre, uma vez que a decisão de abrir o novo empreendimento foi motivada por duas questões nada racionais ou controláveis: o acaso e a paixão.

A paixão de Marcos Willian por café teve início na infância, quando aprendeu a apreciar a bebida. Desde então, teve curiosidade em estudar sobre este produto e conhecer melhor sua história e influência econômica e cultural. A paixão é enfatizada no discurso de Marcos, com a informação de que em seu primeiro encontro com Michelle a levou a uma cafeteria. Informa, ainda, que o primeiro objeto que levou para casa foi uma máquina de café, e a primeira coisa que fizeram juntos, enquanto casal, foi preparar um cappuccino.

A decisão de abrir uma cafeteria não é precedida por qualquer estudo técnico. Will (apelido de Marcos e nome da cafeteria) e Michele não estavam satisfeitos em suas respectivas atividades profissionais e vivenciavam um momento de dificuldades financeiras. Na madrugada do dia 10 de abril de 2012 conversavam sobre tal situação quando Michele, lembrando-se da paixão do esposo pelo café, sugeriu que abrissem uma cafeteria na própria casa. Embora fosse apaixonado por café, Will nunca tinha exercido qualquer atividade econômica relacionada a ele. O café era um hobby que buscava compartilhar com amigos e familiares. Comprar utensílios e equipamentos relacionados ao café fazia parte deste hobby.

A cafeteria poderia ser montada ali onde era o próprio quarto do casal, visto que, por uma peculiaridade da construção, o quarto tinha acesso direto à rua por meio de uma pequena escada. A sugestão despertou em Will o 'efeito Eureka'. Ele, que nunca havia pensado em empreender abrindo uma cafeteria, foi imediatamente consumido por esta ideia e ameaçou se levantar, naquela mesma madrugada, para imediatamente começar a reorganizar o quarto, fazer medições, começar a desmontar seu guarda-roupa, e tomar outras providências. Michele o convenceu a esperar o dia amanhecer.

Este relato evidencia o envolvimento emocional do casal, em especial de Will, na decisão pela abertura de seu pequeno negócio familiar, bem como o acaso que envolve tal decisão. Não há planejamento, não há estudo, não há racionalidade instrumental típica do paradigma funcionalista. Vemos neste relato improviso, reação, luta pela sobrevivência, bagagem histórica, emoções e sentimentos. Não se percebe qualquer preocupação em relação a uma proposta de valor voltada aos interesses dos clientes, mas sim de valor para os próprios empreendedores.

\subsection{Segmento de clientes: quais segmentos de clientes serão foco de sua empresa?}

Três pontos nos chamam atenção neste quesito. O primeiro é que não houve planejamento para a adequação do negócio a clientes prospectados, pois não sabiam quais clientes chegariam até o local. Não planejaram o negócio, não pensaram em uma estrutura anterior. Will conta que logo na primeira semana de abertura da cafeteria saiu distribuindo na rua um cartão, que ele mesmo elaborou, para todas as pessoas que passavam na região. Ele diz: "Ai eu comecei a entregar cartão. Sai na rua, e comecei a entregar”. Não selecionava para quem, apenas divulgava no bairro operário onde morava. 
Will chegou a fazer uma pequena pesquisa com amigos, parentes e vizinhos, pessoas que estavam mais próximas a ele no momento, buscando a opinião dos mesmos quanto ao negócio que estava para iniciar. Todas as opiniões foram negativas. Aconselharam-no a não abrir o empreendimento, seja pelo local inadequado, por não haver público para o tipo de serviço ou por não apostarem no seu preparo para tal negócio.

A família de Michele chegou a sugerir que eles optassem por abrir um 'espetinho', mais adequado ao perfil de moradores do bairro operário. Ele conta: "Todo mundo falava que aqui era bairro periférico. Vou rasgar essa pesquisa e vou seguir meu coração e intuição”.

O segundo, é que o casal relata uma grande variedade de clientes, de vários setores e estilos, investindo em um leque de clientes bastante plural. Eles não delimitam e elegem um público específico. Como dizem: "Eu estimulei e atraí cultura, música, negócio, comemoração, debate, público acadêmico, professores e estudantes. Músicos. Aqui rola músicas temáticas. Atraio público de pub. Mas isso não sei se é estratégico. Eu queria o que eu gostaria para mim."

Por fim, a terceira questão é que dizem considerar seus clientes como amigos. Will diz: "Eu não vendo café. Café é uma desculpa esfarrapada para fazer amigos". Pensam o negócio como expansão de sua casa e, de fato, o negócio funciona no imóvel onde residem, e as pessoas que recebem ali são pessoas que gostariam de tê-las mais próximas. "Acabou que atrai o que gostaria para mim. Não foi intencionalmente, não foi comercialmente, não...". Destacamos assim o não planejamento, a não segmentação de mercado, a entrega à intuição e a afetividade como vínculo com seus possíveis clientes.

\subsection{Os canais: como o cliente compra e recebe seu produto e serviço?}

O canal de venda e distribuição dos produtos da Will Coffee é a própria cafeteria, no caso, o local da prestação do serviço. O que vemos neste quesito que se diferencia do esperado é fato de a cafeteria ser a casa do casal. Will e Michele transformaram a própria casa no local de trabalho, venda e prestação do serviço.

Eles contam como foram, pouco a pouco, transformando cada ambiente, a começar pelo próprio quarto onde dormiam. Will não tinha recursos suficientes para investir e necessitou improvisar. Providenciou a instalação de uma pia no antigo quarto e precisou financiar a pedra a ser utilizada na mesma, já que seus recursos eram escassos. Comprou tijolos, cimento, tinta e areia, e começou a construir, ele próprio, o balcão onde atenderia os futuros clientes. Em um 'topa-tudo' comprou algumas pequenas mesas e cadeiras de madeira, usadas, que necessitavam de pequenos reparos, os quais ele próprio providenciou, deixando-as com uma aparência renovada. Decoraram o ambiente interno com objetos já disponíveis em casa, tornando-o aconchegante. Will, que também é um artista amador, desenhou e pintou alguns tijolos na parede de entrada, transformando a fachada do novo negócio em algo diferente e convidativo.

Futuramente a cafeteria ampliaria seu espaço para outros cômodos do imóvel. Sem recursos para investimento, Will os decorou com sua arte. Will teve a intuição de pintar as paredes internas com café expresso, o que lhes deixou com um tom sofisticado de envelhecimento. Também teve a ideia de revestir as paredes do pequeno banheiro com páginas de revistas em quadrinhos, proporcionando a este cômodo um ar divertido, além de esteticamente interessante. Nas grandes janelas basculantes utilizou fitas adesivas e papel de cor preta, que recortados cuidadosamente deram forma a uma grande cidade vista em perspectiva panorâmica, inspirada na Gothan City das revistas em quadrinhos das histórias do personagem Batman.

Como não disponham de possibilidades financeiras para arcar com os custos de um imóvel comercial mais adequado ao perfil de negócio que estavam empreendendo, improvisaram com o que tinham em mãos, e de acordo com o que poderiam fazer.

\subsection{Relacionamento com clientes: como a sua empresa se relaciona com cada segmento de cliente?}

Como identificado anteriormente, a Will Coffee acolhe uma gama bastante diversificada de clientes. Will comenta que recebe adolescentes que gostam da música, acadêmicos que buscam um bom café, ou mesmo especialistas que buscam conhecer sobre as técnicas e processos de elaboração. Soma-se a este público pessoas que se interessaram em conhecer um lugar diferente dos empreendimentos típicos daquela região. No entanto, não priorizam estratégias por grupos ou segmentos. Ressaltam a importância do atendimento individual, um a um, e para cada um como se fosse único. Will fala de ritual. Ritual em que tem o prazer de "fazer o café para você como se fosse o único café da minha vida e você fosse o único cliente”. 
Destaca-se assim a atenção que Will e Michele dão à recepção, ao atendimento e ao acolhimento de cada cliente. Para eles, esta atenção é o grande diferencial do negócio. O segredo do sucesso até então. Eles falam de coração, emoção, namoro e mística. Falam de envolvimento, carinho e afetividade. Falam do prazer em atender que vai além do interesse econômico e comercial. Falam da importância do reconhecimento como maior recompensa do trabalho que possuem. Conceitos que não podem ser medidos como questões instrumentais. Conceitos que perpassam a ordem das afetividades. Will explica seu negócio com as seguintes palavras: "Eu falo de coração, emoção, quase um namoro".

O casal ressalta que não há técnica sem emoção. Eles explicam que, sozinhos, fazem de tudo ali, desde a recepção, atendimento, preparo das bebidas, caixa e despedida. Cuidam de tudo. E ressaltam: "A técnica é importante, mas não sem emoção. Técnica e emoção".

Ao ouvir o depoimento do casal percebemos que há outra conexão entre trabalho e vida para eles. Há uma resistência ao trabalho tradicional, ao tipo de trabalho com hora e serviço determinado, mas que salientam um processo cotidiano de cuidado, envolvimento e aprendizagem constantes. O trabalho, para eles, abrange outras dimensões da vida. Não há uma separação estanque e determinada. Hora de começar e hora de terminar. E isso se dá pelo envolvimento emocional dos empresários, muito frequente nos casos de empreendedores.

Poderíamos elaborar uma reflexão crítica da incorporação da vida ao trabalho totalizante, mas, também, seria interessante perceber o quanto o uso de uma racionalidade instrumental e funcionalista para entender estes casos é limitada e castradora. Os motivos para tamanho envolvimento com o negócio criado são ilimitados e muito difíceis de serem enquadrados a padrões de comportamento.

\subsection{Atividade-chave: quais são as atividades essenciais para que seja possível entregar a Proposta de Valor?}

Will destaca três pontos como principais para a entrega do valor de sua proposta. Em suas palavras: "Abordagem, atendimento e saída. Nesta ordem de importância".

Ele fala da importância de acolher o cliente desde a chegada até a despedida na porta. O receber, o escutar, o acolher, o ensinar sobre o produto e o acompanhar o cliente na hora de sair. No que tange ao produto, ressalta a importância da qualidade do grão e da técnica de preparo. Mas enfatiza que sem a abordagem e o atendimento, esta qualidade é em vão.

Mais uma vez, Will sobrepõe a relação à técnica. Ressalta que uma não existe sem a outra. No entanto, as relações, no seu estabelecimento, são o grande valor. Na entrevista, ele diz: "Primeiro, abordagem. Segundo, atendimento. Em qualquer lugar, a sua relação acaba quando você paga. Aí, você evapora. Passa a ser invisível. Aqui não. Quando você vai embora, vou com você. Bato papo na saída. Quase um imã. A abordagem, atendimento e saída. E o atendimento tem um tanto de coisa. O produto. Mas são estas três coisas. As vezes tem produto por aí, mas não tem atendimento. Abordagem, mas não tem a saída. Dificilmente você vai embora sozinho. Um tanto de amigos que a gente tem". Will e Michele agregam valor ao negócio, de forma intuitiva e espontânea, ao receber seus clientes como quem recebe uma visita em casa. E de fato recebem, já que residem no mesmo imóvel onde funciona a cafeteria.

\subsection{Recursos principais: quais são os recursos necessários para realizar as atividades-chave?}

Will diz que vende café, momentos e conhecimento. Diz que para entregar seu serviço ao cliente, ele estuda muito. Oferece onze técnicas diferentes de preparo de café coado. E, para ele, é importante explicar como o café é feito, o porquê é feito daquela maneira, quais são as técnicas e os rituais envolvidos. Percebe-se que há primazia na forma de fazer e no conhecimento por traz desta entrega. Ele explica: "Os cafés são rituais de campeonatos mundiais. Eu preparo meu café como se fosse um campeonato. Eu acho um desperdício meu cliente não saber qual é o método para o preparo daquele café”.

Quando Will e Michele falam e descrevem as atividades que englobam seu negócio, falam da paixão pelo café e descrevem todo o contexto de inspiração, coragem, ousadia, determinação e sonho que o 'momento', ao qual se referiu anteriormente, é composto. Para que a atividade-chave seja possível, no caso, a venda de um bom café, o 'momento', a recepção e a entrega para o cliente deve ser realizada com muita empatia e cuidado.

Quando Will descreve o início do negócio, a ideia inicial, descreve como uma inspiração de luz. Emocionado diz que: "Um absurdo que invadiu minha existência”. Um absurdo, nada planejado ou racional, um impulso do momento. Da mesma forma, vai descrevendo as iniciativas que compõem os serviços da cafeteria, os acompanhamentos, a música e a decoração. 
O não planejamento formal é a regra de sua descrição. Na manhã seguinte a aquela madrugada do dia 10 de abril de 2012, o quarto do casal foi desmontado e transferido para outro espaço do imóvel. Will e Michele começaram a separar móveis e utensílios que poderiam ser utilizados na cafeteria. Não tinham nenhum equipamento profissional. Will tinha uma pequena máquina doméstica de café expresso, que seria utilizada enquanto não tivessem condições de comprar máquinas profissionais. Utilizaram os móveis e utensílios da própria casa na cafeteria. As mesas e as cadeiras foram compradas em um 'topa-tudo' e foram reformadas pelo próprio Will, visto que não dispunham de recursos para comprar mobiliário novo. Não tinham geladeira própria para a cafeteria. Neste contexto de improvisação e escassez de recursos financeiros, abriram a cafeteria para o público em apenas duas semanas.

Will diz ser preciso muita confiança em si mesmo, ser necessário ouvir sua própria intuição. Diferente do que o mainstream em Administração diz sobre a necessidade de planejar, de realizar uma análise de investimento ao empreender, de fazer pesquisas de mercado. Will aconselha não ouvir as pessoas e seguir seu próprio coração. Para ele: "Quando a gente sentir uma coisa do coração, faça. Não fica seguindo opinião não .... O risco é o preço do sucesso. Eu arrisquei”. Ele também comenta sobre a necessidade de pensamento positivo. E que esta posição contamina os outros. Ele diz que já tinha uma cafeteria dentro dele e que isso contagiou Michele.

\subsection{Parcerias principais: quais são as atividades-chave realizadas de maneira terceirizada e os recursos principais adquiridos fora da empresa?}

Não identificamos atividades-chaves realizadas de forma terceirizada e os principais recursos adquiridos fora da empresa são o próprio grão de café, a máquina de café e produtos alimentícios. O casal conta que no início do negócio não tinham condições de comprar ou acessar produtos de qualidade, um grão premiado ou uma máquina profissional. Iniciaram com o que tinham em casa. Explicam que, pouco a pouco, foram melhorando a qualidade dos produtos comprados.

Entretanto, Will e Michele não falam muito sobre as relações com os parceiros, fornecedores ou serviços para a manutenção do negócio. Will comenta sobre as feiras nacionais e internacionais sobre café e também sobre donos de cafeterias e especialistas que frequentam o local. Fica explícita a admiração de Will por alguns e a troca de conhecimentos que ocorre entre eles. Will os considera parceiros e, em momento algum, ele encara estas pessoas como concorrentes ou como detentores de fatias de mercado que ele não alcança. Will não fala de competição, reserva de mercado, defesa de saberes. Ao contrário, fala de partilha, troca, admiração pelo negócio do outro. Dessa forma, neste tópico ressaltamos os donos de cafeterias e especialistas do ramo como as principais parcerias da Will Coffee, fontes de trocas de saberes e técnicas, importantes para o negócio.

\subsection{Fontes de receita: quais são as formas de obter receita por meio de propostas de valor?}

Se analisarmos de forma fria o negócio da Will Coffee, poderíamos afirmar que a fonte de receita do empreendimento é a venda de café. No entanto, após a análise das narrativas dos proprietários, não podemos deixar de citar como receita e retorno aos acionistas: saúde física e mental e o reconhecimento do trabalho.

Assim, as fontes de recursos monetários diretos constituem a venda do café expresso, do café coado nos diferentes métodos adotados na cafeteria, na venda de drinks alcoólicos e não alcoólicos feitos à base de café, e das comidas (quitandas) que os acompanham. Receitas que a própria Michele prepara. Valorizam a especialização da casa e não pretendem vender outros tipos de bebidas além do café e de bebidas que podem acompanhá-lo, sem tirar o café de seu lugar de importância, como aconteceria se vendessem bebidas alcoólicas (as bebidas alcoólicas presentes no estabelecimento são utilizadas exclusivamente no preparo de drinks à base de café), ele explica.

Os outros retornos podem ser classificados como indiretos, mas, de forma alguma, menos importantes. Will comenta: "Fiz um mundo que eu sempre gostei de frequentar, mas eu não tinha. Via só nos filmes". Em outro momento, afirma: "A cafeteria dá pra gente uma saúde mental e física. Não temos doença mental. Temos uma fadiga física, por causo do trabalho, mas nada que uma semana de férias não recupere”.

Will e Michele explicitam, em toda a entrevista, o gosto e a paixão pelo trabalho, pelo que fazem, pelo reconhecimento deste esforço que os alimenta. Michele descreve a importância que o reconhecimento, o carinho, o acolhimento e a qualidade do serviço tem para ela. Diz que se alimenta deste reconhecimento. "Reconhecimento que faz a gente acordar de manhã, o dia tá lindo, e vamos. Coisa de chorar”. Ela conta que, no dia anterior, recebeu uma mensagem de uma cliente agradecendo a cafeteria por existir, de estar próxima dela, pois a cliente se sente única na cafeteria. 
No mesmo sentido, o casal se orgulha pelo reconhecimento que a cafeteria tem no mercado de café, bem como, na cidade onde estão localizados. Comentam que foram reconhecidos por mais de cinquenta (50) países, que se reconhecem como a primeira cafeteria de Contagem que entrou para a história, representando a cidade nacional e internacionalmente.

\subsection{Estrutura de custos: quais são os custos relevantes necessários para que a estrutura proposta possa funcionar?}

Este quesito é um dos que mais chamam a atenção. Will e Michele desmistificam a necessidade de grandes aportes de capital, de um planejamento financeiro complexo, de investimento em fluxo de caixa. Começaram com o que tinham à disposição, com as coisas de casa. Os investimentos necessários, como a construção do balcão de atendimento, a instalação da pia de cozinha no antigo quarto do casal, a compra do jogo de mesas e cadeiras para os clientes, foram feitos com pouco recurso. Will fez ele próprio todas as reformas necessárias, dispensando a contratação de terceiros. Decoraram o ambiente com o que tinham disponível em casa e aproveitaram os dotes artísticos de Will para auxiliar nesta questão.

Depois de um ano, ele vendia dez (10) para ganhar dez e cinquenta (10,50), ele explica (simbolicamente). Não tinham lucro significativo, mas o negócio já pagava os próprios custos. Pouco a pouco, foram conseguindo estruturar melhor a casa e comprar uma máquina profissional italiana de café expresso, substituindo a pequena máquina doméstica usada no começo do negócio. Compraram, também, um moedor profissional de café. Isto lhes possibilitava moer os grãos na hora de preparar o café para os clientes, espalhando um odor agradável pelo ambiente e conferindo ao café um sabor especial. Will e Michele puderam comprar grãos especiais, de alto padrão de qualidade, para usar na cafeteria.

Na semana em que completariam 1 ano de funcionamento, o casal recebeu uma ligação de uma equipe de reportagem da unidade mineira do G1, do grupo Globo, querendo registrar a história inusitada da Cafeteria Will Coffee. Um de seus clientes mais assíduos era funcionário daquela redação e havia contado a história daquele negócio ao editor, despertando-lhe curiosidade. A reportagem foi publicada no site da Globo Minas em 13 de abril de 2013 com o seguinte título: "Casal transforma quarto em cafeteria e atrai clientes em Contagem" (Antunes, 2013).

A reportagem despertou a curiosidade das pessoas e atraiu clientes para a cafeteria. A equipe editorial do G1, em nível nacional, gostou da matéria e a republicou em sua página, ampliando o alcance da divulgação da cafeteria, o que levou a matéria a ser republicada em nível internacional por outros agentes da mídia. Os donos da cafeteria foram procurados por outros órgãos de imprensa e passaram a conceder novas entrevistas e a participar de programas de televisão como convidados. A publicidade espontânea tornou a cafeteria conhecida entre os amantes de café e ela passou a ser visitada por pessoas que se deslocavam de longe para conhecer o negócio, tornando-o lucrativo.

\section{CONSIDERAÇÕES FINAIS}

A gestão ordinária não é apresentada como um ‘modelo’ alternativo de gestão, tampouco como um método formal de pesquisa. Nossa perspectiva é de crítica aos modelos e postulados gerenciais dominantes, que buscam simplificar a realidade complexa do ambiente sócio-organizacional e, ao fazer isso, silenciam, desprezam, apagam os aspectos dessa realidade complexa que não conseguiram restringir aos modelos propostos. A visão gerencial dominante despreza o conhecimento do sujeito comum, relegando-o a um conhecimento não adequado enquanto gestão. A racionalidade instrumental estigmatiza padrões tidos como adequados e simplifica comportamentos.

A partir do caso da Cafeteria Will Coffee demonstramos que o cotidiano organizacional é rico de possibilidades, de criatividade e de subversão aos valores da cultura do management. A gestão ordinária praticada no cotidiano daquele negócio, desde sua concepção, demonstrou a importância que deve ser conferida à observação de cada um desses gestores ordinários no seu dia a dia, para além dos papéis predefinidos pela própria teoria de administração dominante.

Os modelos gerencialistas estabelecidos pelo mainstream, tidos como universais, não se aplicaram ao caso da Cafeteria Will Coffee. No pequeno negócio em estudo, encontramos o predomínio da espontaneidade, do improviso, do fazer com o que se tem em mão; do compartilhamento de conhecimento; do agir e do responder ao ambiente sem planejamento prévio; com tempo estendido de dedicação aos clientes e parceiros; a não adoção de protocolos e procedimentos pré-estabelecidos; a não análise de mercado; uma gestão não orientada por modelos e pela produtividade; a presença da afetividade; da razão substantiva; a valorização da intuição. 
Todas essas práticas podem estar presentes no dia a dia da maioria dos trabalhadores que são desconsideradas pelas estruturas formais de ensino e de pesquisa sobre organizações, como se os seres humanos ali existentes apresentassem comportamentos maquinais.

Na gestão ordinária valoriza-se a multiplicidade das individualidades, das experiências, das práticas e dos discursos dos sujeitos. Surge, então, a possibilidade de trabalhar o diálogo e seus significados, existente nas narrativas construídas pelos sujeitos no seu cotidiano (Gabriel, 2004), nas suas várias formas de organizar seus negócios (Carvalho, 2006), com suas redes de relações, suas estratégias/táticas de sobrevivência. Seguimos Carvalho (2006) quando este aponta que a gestão deveria ser vista em toda sua diversidade. Na mesma direção, concordamos com Misoczky e Vecchio (2006), Xavier et al. (2012) e Barros e Carrieri (2015) que sugerem o uso do verbo 'organizar' ao invés de 'organização', pois este representaria mais a busca da dinâmica e não algo dado, estabelecido.

Como sugestão para novas pesquisas atentas à gestão ordinária, ressaltamos a importância da valorização de métodos qualitativos de análise dos casos, das narrativas, dos estudos de vidas de pessoas comuns que se proponham a expandir o que reconhecemos como experiência organizacional. Principalmente, as experiências de pessoas comuns; as pesquisas atentas às especificidades concretas do sul global, regionais e locais, contextualizadas em suas dificuldades. Atenção às práticas de mulheres, negros, indígenas, transsexuais, todas as 'minorias', que muitas vezes estão invisibilizadas pelos cargos que ocupam e pelo lugar simbólico que a sociedade lhes destina. Atenção aos problemas do dia a dia e às resoluções imediatas, bem como o encorajamento para a exposição e partilha dos erros, dos desvios e dos contornos dados. Por fim, atenção às redes de confiança entre as equipes de trabalho e seus métodos de partilha de acertos e erros cotidianos, o que nos encaminhará para propostas onde a aprendizagem e a criação coletiva local sejam possíveis.

\section{REFERÊNCIAS}

Ahrens, T. (2009). Everyday accounting practices and intentionality. In Chapman, C. Cooper, D., \& Miller, P. Accounting, Organizations, and Institutions. Oxford: Oxford University Press, p. 30-47. DOI:10.1093/ acprof:oso/9780199546350.001.0001.

Antunes, S. (2013). Casal transforma quarto em cafeteria e atrai clientes em Contagem. G1 Minas Gerais. Disponível em: http:/g1.globo.com/minas-gerais/noticia/2013/04/casal-transforma-quarto-em-cafeteria-eatrai-clientes-em-contagem.html

Barros, A. N., Cruz, R. C., Xavier, W. S., Carrieri, A. P., \& Lima, G. C. O. (2011). Apropriação dos Saberes Administrativos: Um Olhar Alternativo sobre o Desenvolvimento da Área. Revista de Administração Mackenzie, 12(5), 43-67. DOI: https://dx.doi.org/10.1590/S1678-69712011000500003.

Barros, A., \& Carrieri, A. P. (2015). O cotidiano e a história: construindo novos olhares na administração. RAERevista de Administração de Empresas, 55(2). DOI: http://dx.doi.org/10.1590/S0034-759020150205.

Benjamin, W. (2006). Passagens. Belo Horizonte, São Paulo: UFMG/Imprensa Oficial do Estado de São Paulo.

Berger, P. L., \& Luckmann, T. (2011). A construção social da realidade: tratado de sociologia do conhecimento. $33^{\mathrm{a}}$ ed. Petrópolis: Vozes. DOI: http://dx.doi.org/10.5433/1980-511X.2017v12n2p316.

Bertero, C; Alcadipani, R.; Cabral, S.; Faria, A. \& Rossoni, L. (2013). Os Desafios da Produção do Conhecimento em Administração no Brasil. Cadernos EBAPE (FGV), (11), 181-196.

Carneiro, A., \& Barros, A. (2017). Uso de documentos para narrar a história de organizações: reflexões e experiências. Revista de Contabilidade e Organizações, 11(30), 14-23. DOI: https://doi.org/10.11606/rco. v11i30.134408.

Carrieri, A. P., Perdigão, D. A., \& Aguiar, A. R. C. (2014). A gestão ordinária dos pequenos negócios: outro olhar sobre a gestão em estudos organizacionais. Revista de Administração, 49(4), 698-713. DOI: https://dx.doi. org/10.5700/rausp1178.

Carvalho, C. A. P. (2006). Outras formas organizacionais: o estudo de alternativas ao modelo empresarial na realidade brasileira. Porto Alegre. Projeto Procad/CNPq, 2006.

Carvalho, M.R. de O., \& Fischer, T.M.D. (2006). ARS Antiqua: mosteiro de são bento, o eterno no tempo. Revista de Administração de Empresas, 46(1), 14-28. DOI: https://dx.doi.org/10.1590/S0034-75902006000100003. 
Corbertt-Etchevers, I., \& Mounoud, E. (2011). A narrative framework for management ideas: disclosing the plots of knowledge management in a multinational company. Management Learning, 42(2), 165-181. DOI: https:// doi.org/10.1177/1350507610394579.

De Certeau, M. (1994). A invenção do cotidiano: artes de fazer. Petrópolis: Vozes. DOI: https://doi.org/10.11606/ issn.2236-4242.v0i8p31-45.

De Certeau, M, Giard, L., \& Mayol, P. (1996). A invenção do cotidiano: 2. morar, cozinhar. Petrópolis: Vozes, 2.

Del Priore, M. (1997). História do cotidiano e da vida privada. Domínios da História: ensaios de teoria e metodologia. Rio de Janeiro: Campus, 259-268.

Deleuze, G., \& Guattari, F. (1978). Kafka: por una literatura menor. Ediciones Era.

Didi-Huberman, G. (2011). Sobrevivência dos vaga-lumes. Belo Horizonte: Editora UFMG.

Duran, M. C. G. (2007). Maneiras de pensar o cotidiano com Michel de Certeau. Revista Diálogo Educacional, 7(22), 115-128. DOI: http://dx.doi.org/10.7213/rde.v7i22.4177.

Fischer, T., Davel, E., Vergara, S., \& Ghadiri, P. D. (2007). Razão e sensibilidade no ensino de administração: a literatura como recurso estético. Revista de Administração Pública, 41(5), 935-958. DOI: https://dx.doi. org/10.1590/S0034-76122007000500007.

Foucault, M. (1987). A Arqueologia do saber. Rio de Janeiro: Forense Universitária.

Foucault, M. (2013). De espaços outros. Estudos Avançados, 27(79), 113-122. DOI: https://doi.org/10.1590/ S0103-40142013000300008.

Franklin, W. (2016). Como o modelo CANVAS pode ajudar a estruturar o seu negócio. Recuperado em 12 de outubro, 2018, de https://moip.com.br/blog/como-o-canvas-pode-estruturar-o-seu-negocio/

Gabriel, Y. (2004). Narratives, stories and texts. The Sage handbook of organizational discourse, 61, 77. DOI: https://doi.org/10.4135/9781848608122.n3

Guarinello, N. L. (2004). História científica, história contemporânea e história cotidiana. Revista brasileira de história, 24(48), 13-38. DOI: https://dx.doi.org/10.1590/S0102-01882004000200002.

Hjorth, D. (2005). Organizational Entrepreneurship: With de Certeau on Creating Heterotopias (or Spaces for Play). Jornal of Management Inquirity, 14 (4), 386-398. DOI: https://doi.org/10.1177/1056492605280225.

Holanda, L. A. (2011). Resistência e apropriação de práticas de management no organizar de coletivos da cultura popular. Tese de doutorado, Administração, Propad/UFPE, Recife.

Jeacle, I. (2009) Accounting and everyday life: towards a cultural context for accounting research. Qualitative Research in Accounting \& Management, 6 (3), 120-136. DOI: https://doi.org/10.1108/11766090910973894.

Levigard, Y. E., \& Barbosa, R. M. (2010). Incertezas e cotidiano: uma breve reflexão. Arquivos Brasileiros de Psicologia, 62(1), 84-89.

Martins, J. S. (2008). A sociabilidade do homem simples. São Paulo: Hucitec.

Matos, M. I. S. (2002). Cotidiano e cultura: história, cidade e trabalho. Bauru: EDUSC.

Mattos, L. C. (2009). Administração é ciência ou arte? O que podemos aprender com este mal-entendido? RAE-Revista de Administração de Empresas, 49(3), 349-360. DOI: http://dx.doi.org/10.1590/S003475902009000300009.

Micklethwait, J., \& Wooldridge, A. (1998). Os bruxos da administração: como entender a babel dos gurus empresariais. Rio de Janeiro: Campus.

Misoczky, M. C. A., \& Vecchio, R. A. (2006). Experimentando pensar: da fábula de Barnard à aventura de outras possibilidades de organizar. Cadernos EBAPE, 4(1), 1-11. DOI: http://dx.doi.org/10.1590/S167939512006000100004 .

Pinheiro, A. S., Carrieri, A. P., \& Joaquim, N. F. (2013). Esquadrinhando a governança corporativa: o comportamento dos personagens sob o ponto de vista dos discursos dos autores acadêmicos. Revista Contabilidade \& Finanças, 24(63). DOI: http://dx.doi.org/10.1590/S1519-70772013000300006. 
Ramos, A. G. (1981). A Nova Ciência das Organizações: uma reconstrução da riqueza das nações. Rio de Janeiro: Editora da FGV.

Santos, L. C. (2014). A narrativa organizacional para a promoção do engajamento. E-Compós, 17(1). DOI: https:// doi.org/10.30962/ec.v17i1.1049.

Saraiva, L. A. S. (2007). Métodos narrativos de pesquisa: uma aproximação. GESTÃO. Org-Revista Eletrônica de Gestão Organizacional, 5(2).

Sousa, A, Filho. (2002). Michel de Certeau: fundamentos de uma sociologia do cotidiano. Sociabilidades, 2, 129134.

Wanderley, S., Barros, A., da Costa, A. D. S. M., \& Carrieri, A. P. (2017). Caminhos e percursos da história em administração: um chamado à reflexão sobre o tempo e a construção do presente. Farol-Revista de Estudos Organizacionais e Sociedade, 3(8), 801-820. DOI: https://doi.org/10.25113/farol.v3i8.3937.

Wood Jr, T., \& Paula, A. D. (2002a). Pop management: a literatura popular de gestão no Brasil. São Paulo: FGV/ EAESP.

Wood Jr, T., \& Paula, A. P. P. D. (2002b). Pop-management: contos de paixão, lucro e poder. Organizações \& Sociedade, 9(24), 39-51. DOI: http://dx.doi.org/10.1590/S1984-92302002000200003.

Xavier, W. S., de Barros, A. N., Cruz, R. C., \& de Pádua Carrieri, A. (2012). O imaginário dos mascates e caixeirosviajantes de Minas Gerais na formação do lugar, do não lugar e do entrelugar. Revista de Administração, 47(1), 38-50. DOI: http://dx.doi.org/10.5700/rausp1024.

\section{Como citar este artigo}

Carrieri, A. de P.; Perdigão, D.; Martins, P.G.; \& Aguiar, A.R.C. (2018). A Gestão Ordinária e suas práticas: o caso da Cafeteria Will Coffee. Revista de Contabilidade e Organizações, 12:e141359. DOI: http://dx.doi. org/10.11606/issn.1982-6486.rco.2018.141359 